\title{
Trace mineral status in Caucasian and South Asian postmenopausal women living in the UK
}

\author{
S. A. Dillon ${ }^{1}$, S. R. Mitra ${ }^{1}$, P. C. Foster ${ }^{1}$, B. Ellahi ${ }^{2}$, J. F. McCann ${ }^{3}$ and N. M. Lowe ${ }^{1}$ \\ ${ }^{1}$ International Institute of Nutritional Sciences and Applied Food Safety Studies, University of Central Lancashire, \\ Preston, PR1 2HE, ${ }^{2}$ Department of Clinical Sciences, University of Chester, Chester CH1 4BJ, UK and \\ ${ }^{3}$ Medical Rehabilitation Centre, Royal Preston Hospital, Preston, PR2 9HT, UK
}

Zinc, Selenium and Copper are essential trace minerals that are important for human health and data suggests there is a high prevalence of inadequate intake in the UK with the prevalence of inadequate intake being higher in females than in males ${ }^{(1)}$. Previous data from this laboratory has also indicated that South Asian (SA) females may be more at risk of micronutrient deficiency than Caucasian (C) females $^{(2)}$. The aim of this study was to investigate this further and conduct a comparative investigation of $\mathrm{Zn}$, Se and $\mathrm{Cu}$ status in postmenopausal SA and C females. Apparently healthy postmenopausal C and SA females of 50-65 years of age and at least one year post menopause were identified for this study. Dietary information was collected using an interviewer administered food frequency questionnaire $(\mathrm{FFQ})^{(3)}$ which was developed to study nutrient intakes of an adult Pakistani, European and African-Caribbean community in inner city Britain. Fasting blood samples were collected and plasma was stored at $-70^{\circ} \mathrm{C}$ until analysis. The $\mathrm{Se}, \mathrm{Cu}$, and $\mathrm{Zn}$ content of plasma samples was measured by inductively coupled plasma-mass spectroscopy (ICP-MS).

\begin{tabular}{lcccc}
\hline & Caucasian (Mean) & SD & South Asian (Mean) & SD \\
\hline Age $(\mathbf{y})$ & 60.04 & 4.3 & 56.31 & 3.5 \\
Zn Intake $(\mathbf{m g} / \mathbf{d})$ & 10.19 & 2.5 & $8.52^{*}$ & 3.1 \\
Cu Intake $(\mathbf{m g} / \mathbf{d})$ & 2.32 & 1.5 & $1.16^{*}$ & 0.3 \\
Se Intake $(\boldsymbol{\mu g} / \mathbf{d})$ & 66.53 & 4.7 & $40.45^{*}$ & 2.5 \\
Zn Intake $(\mathbf{m g} / \mathbf{k J})$ & 1.087 & 0.2 & 1.073 & 0.3 \\
Cu Intake $(\mathbf{m g} / \mathbf{k J})$ & 0.242 & 0.11 & $0.148^{*}$ & 0.03 \\
Se Intake $(\boldsymbol{\mu g} / \mathbf{k J})$ & 6.964 & 2.7 & $5.118^{*}$ & 1.7 \\
Plasma Zn $(\boldsymbol{\mu m o l} / \mathbf{L})$ & 11.03 & 3.5 & 9.46 & 3.4 \\
Plasma Cu $(\boldsymbol{\mu m o l} / \mathbf{L})$ & 14.06 & 2.6 & $15.73^{*}$ & 3.4 \\
Plasma Se $(\boldsymbol{\mu m o l} / \mathbf{L})$ & 0.96 & 0.2 & $0.87^{*}$ & 0.2 \\
\hline
\end{tabular}

Mean values were significantly different from Caucasian: $* p<0.05$.

Results indicate that dietary intake of $\mathrm{Zn}$, Se, and $\mathrm{Cu}$ was significantly lower in the SA compared with the $\mathrm{C}$ females $(p<0.05)$. Significant differences between the two populations were also identified for both $\mathrm{Se}$ and $\mathrm{Cu}$ when mineral intake was normalised to energy intake $(p<0.05)$. When dietary intake levels were compared to the current UK dietary reference values the SA population were found to have an intake of Se that was significantly lower than the DRV $(60 \mu \mathrm{g} / \mathrm{d} ; p<0.05)$. Differences between the two populations were also identified for plasma $\mathrm{Se}$ and $\mathrm{Cu}$; plasma Se was significantly lower and plasma $\mathrm{Cu}$ was significantly higher in the SA compared to the $\mathrm{C}$ females $(p<0.05)$. In contrast to the dietary intake data where $\mathrm{Zn}$ intake was higher than the DRV plasma $\mathrm{Zn}$ fell below the reference range of $12-$ $25 \mu \mathrm{Mol} / \mathrm{L}$ in both the SA and $\mathrm{C}$ females. In conclusion trace mineral analysis of dietary intake and plasma levels revealed differences for $\mathrm{Se}, \mathrm{Cu}$ and $\mathrm{Zn}$ in SA and $\mathrm{C}$ females. Only Se intake in the SA females was a significantly below the DRV and plasma $\mathrm{Zn}$ levels indicate a marginal deficiency in both populations.

1. Vinas BR, Barba LR, Ngo J et al. (2011) Ann Nutr Metab 59, 84-95.

2. Lowe NM, Mitra SR, Foster PC et al. (2010) Br J Nutr 103, 1706-1710.

3. Vyas A, Greenhalgh A, Cade J et al. (2003) J Hum Nutr Dietet 16, 327-337. 